\title{
National Prevalence of Micronutrient Deficiencies, Anaemia, Genetic Blood Disorders and Over- and Undernutrition in Omani Women of Reproductive Age and Preschool Children
}

"Nicolai Petry, ${ }^{1}$ Salima A. Al-Maamary, ${ }^{2}$ Bradley A. Woodruff, ${ }^{3}$ Samia Alghannami, ${ }^{2}$ Saleh M. Al-Shammakhi, ${ }^{2}$ Ibtesam K. Al-Ghammari, ${ }^{2}$ Vilma Tyler, ${ }^{4}$ Fabian Rohner, ${ }^{1}$ James P. Wirth ${ }^{1}$

$$
\begin{aligned}
& \text { الانتشار الوطني لنقص الفيتامينات والأملاح وفقر الدم واضطرابات } \\
& \text { الدم الوراثية و نقص وفرط التغذية الدى العمانيات في سن الإنيات الإنجاب } \\
& \text { والأطفال في سن ما قبل المدرسة اليعلية لمدي العماتيات }
\end{aligned}
$$

نيكولاي بيتري، سليمة المعمرية، برادلي وودرف، سامية الغنامي، صالح الشماخي، ابتسام الغماري، فيلما تايلر، فابيان رونر، جيمس ويرث

ABSTRACT: A national cross-sectional survey was conducted to estimate the prevalence of anaemia, micronutrient deficiencies, haemoglobin disorders and over- and undernutrition in children and women of reproductive age in Oman. Wasting and stunting were found in $9.3 \%$ and $11.4 \%$ of children aged $0-59$ months, respectively, while $4.2 \%$ were overweight or obese. In addition, $23.8 \%$ were anaemic and $10.2 \%, 9.5 \%$ and $10.6 \%$ had iron, vitamin A and vitamin D deficiencies, respectively. Sickle cell and $\beta$-thalassaemia genetic traits were present in $5.3 \%$ and $4.2 \%$ of children and $4.7 \%$ and $2.8 \%$ of women, respectively. Overall, $9.1 \%$ of Omani women were underweight and $59.2 \%$ were overweight or obese. The prevalence of anaemia was 27.8\%, while iron, folate, vitamin B12 and vitamin D deficiencies affected 24.8\%, 11.6\%, $8.9 \%$ and $16.2 \%$, respectively. Anaemia among both children and women and the prevalence of overweight and obesity in women are the most concerning nutritional problems in Oman.

Keywords: Nutrition Disorders; Malnutrition; Micronutrients; Iron-Deficiency Anemia; Avitaminosis; Vitamin D Deficiency; Vitamin B 12 Deficiency; Oman.

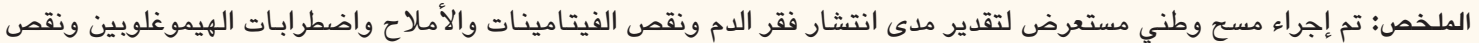

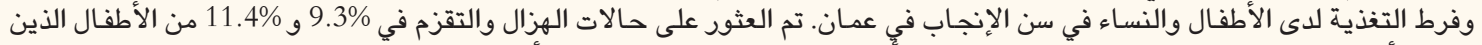

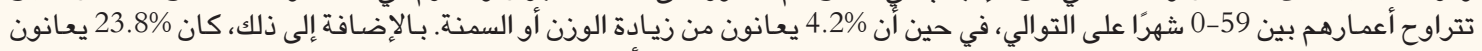

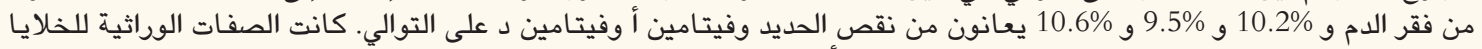

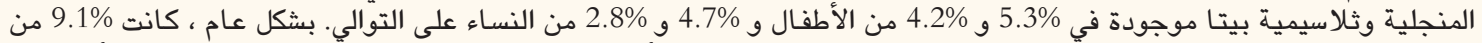

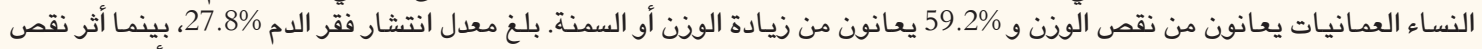

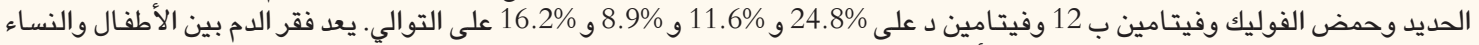
وانتشار الوزن الزائد والسمنة لدى النساء من أكثر المشاكل الغذائية المتعلقة بسلطنة عمان.

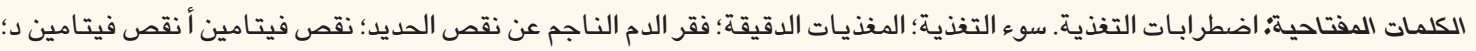
نقص فيتامين ب 21؛ سلطنة عمان.

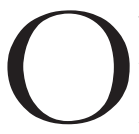

VER THE LAST FEW DECADES, OMAN HAS undergone rapid economic growth and was ranked by the United Nations as the most improved nation in the world in terms of human development between 1970 and 2010. ${ }^{1}$ This was accompanied by a consistent decline in the national prevalence of stunting, wasting and underweight in young children; moreover, the prevalence of undernutrition in non-pregnant women also declined during this period, albeit somewhat inconsistently. ${ }^{2-4}$ However, a recent study examining global trends between 1980-2013 reported that 73.4\% of Omani women were overweight or obese, with Oman experiencing one of the largest prevalence increases in obesity worldwide. ${ }^{5}$ In contrast, the prevalence of other nutritional deficiencies among Omani women has remained stable. As a result, Oman may face nutritional health issues with regards to both overand undernutrition.

While the prevalence of anaemia has declined in women, this is not the case among children., ${ }^{3,46}$ 
According to the World Health Organization (WHO), anaemia is a moderate public health problem for Omani women and a severe public health problem for Omani children. ${ }^{7}$ Anaemia is a multifactorial condition that can lead to reduced working capacity, an increased risk of maternal and perinatal mortality and morbidity, adverse pregnancy outcomes, reduced educational achievements and poor cognitive performance. ${ }^{8}$ Aside from nutritionally-induced anaemia resulting from iron, folate and/or vitamin B12 deficiencies, the major causes of anaemia in Middle Eastern countries are haemoglobin disorders, such as $\beta$-thalassaemia and sickle cell anaemia, as well as infection. ${ }^{9}$

Iron deficiency (ID) and vitamin A deficiency (VAD) are among the most prevalent micronutrient deficiencies worldwide, particularly affecting young children and women of reproductive age. ${ }^{10,11}$ In Oman, the last nutrition assessment in 2004 reported a high prevalence of ID in women and children and moderate levels of VAD in children, but not women. ${ }^{12}$ Vitamin D deficiency (VDD) might also be an issue in Oman; however, VDD status has never been assessed on a national level.

In order to understand the current nutritional situation in Oman, the Oman National Nutrition Survey (ONNS) was conducted from December 2016 to April 2017. The ONNS investigated the prevalence and severity of certain nutrition-related conditions, including undernutrition, overnutrition, anaemia, micronutrient deficiencies and certain genetic blood disorders (i.e. sickle cell disease/traits and $\beta$-thalassaemia). This information is intended to help with the revision of existing nutrition-related programmes in Oman and the five-year health development plan of the Ministry of Health. The current article presents and interprets ONNS data with regards to the prevalence of various forms of malnutrition in Oman.

\section{Methods}

\section{SURVEY DESIGN AND PARTICIPANTS}

The ONNS was conducted between December 2016 and April 2017 as a subset of a national survey of chronic diseases and risk factors. The sampling procedure and study design of the national survey utilised the STEPwise approach advocated by the WHO. ${ }^{13}$ For both surveys, each of the 11 governorates in Oman was considered a separate survey stratum. Equal numbers of blocks within these governorates were identified and were selected at random from the 2010 Oman census; following this, random individual households were selected within these census blocks. The household lists of the selected census blocks were updated prior to the randomised selection process.

In the national chronic diseases survey, households were selected at random without regard to the citizenship of household members. However, the ONNS included only Omani households because Omani citizens are the primary beneficiaries of national public health programmes. Thus, a random sample of Omani households among those included in the national chronic diseases survey was selected from each governorate separately via simple random sampling. A total of 375 Omani households were included from each governorate, as a priori sample size calculations indicated that this number would contain adequate numbers of Omani women and children to sufficiently precise estimates of nutrition indicators. However, in Muscat Governorate, the national chronic diseases survey contained only 318 Omani households; accordingly, all of these households were selected for inclusion in the ONNS.

\section{DATA COLLECTION AND LABORATORY ANALYSIS}

One week prior to data collection, all field workers (including supervisors, team leaders, interviewers, phlebotomists, anthropometry specialist and laboratory technicians) received both classroom and practice training on data and specimen collection procedures. The classroom training was followed by two days of field testing in two census enumeration areas in Muscat which were not part of the ONNS sample.

Interviews were conducted at selected households, starting with the household questionnaire, which was either administered to the head of the household or another knowledgeable adult. This questionnaire included modules related to household demographic variables, income and water, sanitation and hygiene practices. Respondents were also asked about the usual frequency of purchasing cooking oil and wheat flour and the usual quantity purchased each time. These data were used to calculate average household consumption. Individual consumption was calculated per adult male equivalent (AME) based on the members of each household, using age- and gender-specific categories proposed by the United Nations Food and Agriculture Organization. ${ }^{14}$

Following this, individual questionnaires were administered to pregnant women of any age, caretakers of children aged 0-59 months and non-pregnant women aged 15-49 years. For children, the questionnaire included questions regarding the children's dietary diversity, history of recent illnesses, consumption of fortified foods and micronutrient supplements and level of sun exposure. For the pregnant and 
non-pregnant women, the questionnaires collected information regarding marital status, educational level, dietary diversity, recent supplement consumption, knowledge of fortified foods and attitudes and behaviours.

Following the completion of all the interviews in the household, height and weight measurements were taken from all non-pregnant women and children in the household, while mid-upper arm circumference (MUAC) measurements were taken from pregnant women and children. Weight was measured using electronic scales (SECA, Hamburg, Germany). Children who could not stand alone on the scale were measured while in their caretakers' arms, with the weight of the former calculated using the tare function to subtract the weight of the latter. Both children and women were weighed while wearing light clothing. Length or height was measured using wooden height/length boards (United Nations International Children's Emergency Fund [UNICEF], Copenhagen, Denmark). The length of children younger than two years old was measured while they were lying down.

Blood samples were collected from children aged 6-59 months and women aged 15-49 years in 50\% and $25 \%$ of the selected households, respectively, in all governorates but Muscat, where children in all households and women in 50\% of households were included. Such households were randomly designated prior to data collection. In non-phlebotomy-designated households, only haemoglobin concentrations were measured for all children aged 6-59 months and non-pregnant and pregnant women using the third drop of capillary blood collected from the individual's finger with a finger stick, or a heel stick for children aged 6-11 months. Haemoglobin concentrations were measured on-site using a portable point-of-care haemoglobinometer ( $\mathrm{Hb} 301+$ Analyser, HemoCue ${ }^{\mathbb{R}} \mathrm{AB}$, Ängelholm, Sweden). HemoCue quality control material (low, medium and high concentration) was used on a daily basis and results recorded in a control form.

Among children selected for a phlebotomy, a total of $4 \mathrm{~mL}$ of blood was collected in an ethylenediaminetetraacetic acid (EDTA)-coated vacutainer (Becton Dickinson, Franklin Lakes, New Jersey, USA) to obtain plasma for the analysis of micronutrient biomarkers and whole blood to measure markers of haemoglobinopathies. In non-pregnant women, blood was collected in two vacutainers: (1) $2 \mathrm{~mL}$ of blood was collected into an EDTA-coated vacutainer to measure markers of haemoglobinopathies and (2) $4 \mathrm{~mL}$ of blood was collected into a clotting-activator serum vacutainer to measure micronutrient biomarkers. Following on-site haemoglobin measurements, labelled tubes containing whole blood were placed in cool boxes at $2-8^{\circ} \mathrm{C}$ and transported to regional laboratories for processing within 24 hours. Cold boxes were refilled with ice packs on a daily basis and were equipped with thermometers to continuously monitor internal temperatures.

For children, $0.5 \mathrm{~mL}$ of whole blood was taken out of the vacutainer prior to centrifugation to measure markers of haemoglobinopathies. For women, the EDTAcoated vacutainer was used for the analysis of haemoglobinopathies. For micronutrient analyses, blood tubes were centrifuged at 3,000 rpm for seven minutes to separate the plasma (in children) or serum (in women) from the blood cells and then aliquoted into labelled blood tubes and stored in freezers at $-20^{\circ} \mathrm{C}$ until they were packed in dry ice and sent to international laboratories for analysis. No blood samples were taken from children under six months of age.

Plasma and serum were analysed for ferritin, retinol-binding protein (RBP), C-reactive protein (CRP) and $\alpha 1$-acid glycoprotein (AGP) at the VitMin Laboratory (Wilstätt, Germany) using an enzymelinked immunosorbent assay. ${ }^{15}$ Plasma and serum 25hydroxycholecalciferol concentrations were measured using tandem liquid chromatography (LC) mass spectrometry at the Khatib Micronutrient Laboratory (Amman, Jordan). This laboratory also measured plasma folate and vitamin B12 concentrations in women via electrochemiluminescence using the $\operatorname{Cobas}^{\circledR}$ e411 automated analyser (Roche Diagnostics, Risch-Rotkreuz, Switzerland).

\section{PARAMETERS AND CLINICAL THRESHOLDS}

Haemoglobin concentrations were adjusted for altitude; however, as only two of the 4,598 women included in the sample stated that they smoked on a daily basis, they were not adjusted for smoking. ${ }^{16}$ Children and pregnant women were considered anaemic if haemoglobin concentrations were $<110 \mathrm{~g} / \mathrm{L}$, with concentrations of <70, 70-99 and 100-109 g/L classified as severe, moderate and mild anaemia, respectively. Non-pregnant women were considered anaemic if haemoglobin concentrations were $<120 \mathrm{~g} / \mathrm{L}$, with concentrations of $<80,80-109$ and $110-119 \mathrm{~g} / \mathrm{L}$ denoting severe, moderate and mild anaemia, respectively. ${ }^{17}$ The weighted prevalence of anaemia in both children and women was used to determine the public health significance of anaemia according to the WHO. ${ }^{17}$ Individuals with severe anaemia were referred to their local health facility for further diagnosis and treatment.

Ferritin and RBP were adjusted for inflammation using CRP and AGP values according to previously reported methods. ${ }^{18,19}$ In children and women, ID was defined as inflammation-adjusted ferritin concentrations of $<12$ and $<15 \mu \mathrm{g} / \mathrm{L}$, respectively. ${ }^{20}$ As $\mathrm{RBP}$ is not a WHO-recommended biomarker for the assessment of vitamin A status, the correlation between RBP results 
and serum retinol was checked by measuring retinol in a subset of specimens using high-performance LC at the Khatib Micronutrient Laboratory. There was a strong correlation between retinol and RBP values upon linear regression analysis. Nevertheless, the kappa coefficient of agreement and the sensitivity were higher when the RBP cut-off for defining VAD was adjusted to 0.73 instead of $0.70 \mu \mathrm{g} / \mathrm{L}$. For this reason, 0.73 and $1.05 \mu \mathrm{g} / \mathrm{L}$ were used as cut-off values to denote deficiency and insufficiency, respectively. ${ }^{21,22}$

Cut-off values for CRP and AGP were $>5 \mathrm{mg} / \mathrm{L}$ and $>1 \mathrm{~g} / \mathrm{L}$, respectively. Inflammation status was defined as follows: no inflammation, incubation (elevated CRP only), early convalescence (elevated CRP and AGP) and late convalescence (elevated AGP only). ${ }^{18,19}$ In non-pregnant women and children, VDD was defined using a cut-off value for 25-hydroxycholecalciferol of $<30 \mathrm{nmol} / \mathrm{L}$; for vitamin D insufficiency (VDI), the cut-off value was set at $50 \mathrm{nmol} / \mathrm{L} .{ }^{23}$ Sun exposure levels were defined according to previously published parameters. ${ }^{24}$ Based on WHO recommendations, plasma folate concentrations of $<10 \mathrm{nmol} / \mathrm{L}$ indicated folate deficiency while vitamin B12 deficiency was set at $<150 \mathrm{pmol} / \mathrm{L}$ for women. ${ }^{25}$

Height-for-age, weight-for-age and weight-forheight were calculated for all children based on the WHO Growth Standard. ${ }^{26}$ All forms of undernutrition were indicated by z-scores of less than -2.0 . Severe and moderate forms of undernutrition were defined by z-scores of less than -3.0 and -3.0 to -2.01 , respectively. Wasting, stunting and underweight were categorised using weight-for-height, height-for-age and weightfor-age z-scores, respectively. Overweight in children was defined by a weight-for-height $\mathrm{z}$-score greater than 2.0 to 3.0, while obesity was defined by a z-score greater than 3.0. The nutritional status of non-pregnant women aged 15-49 years was assessed via body mass index (BMI). Six BMI categories were designated, including severe undernutrition $\left(<16.0 \mathrm{~kg} / \mathrm{m}^{2}\right)$, moderate undernutrition $\left(16.0-16.9 \mathrm{~kg} / \mathrm{m}^{2}\right)$, at risk of undernutrition $\left(17.0-18.4 \mathrm{~kg} / \mathrm{m}^{2}\right)$, normal $\left(18.5-24.9 \mathrm{~kg} / \mathrm{m}^{2}\right)$, overweight $\left(25.0-29.9 \mathrm{~kg} / \mathrm{m}^{2}\right)$ and obese $\left(\geq 30.0 \mathrm{~kg} / \mathrm{m}^{2}\right){ }^{27}$ For pregnant women, a MUAC of $<23.0 \mathrm{~cm}$ was deemed to indicate undernutrition. ${ }^{28,29}$

\section{DATA MANAGEMENT AND STATISTICAL ANALYSIS}

Questionnaire data were entered into a database using EpiData, Version 3.02 (EpiData Association, Odense, Denmark). In order to minimise the risk of data entry errors, the EpiData software was programmed to only accept codes within a certain range specific to each variable; in addition, the data were double-entered and corrected following completion of the field work. Data analysis was performed using the Statistical Package for the Social Sciences (SPSS), Version 24.0 (IBM Corp., Armonk, New York, USA) with the complex survey module. In order to account for the unequal probability of selection, strata-weighted analyses were used for household variables. Moreover, because the sampling fraction for those undergoing phlebotomy differed among governorates, separate sampling weights for women and children were calculated for the results of blood testing. No sampling weights were used when generating governorate-specific estimates.

The household wealth index was calculated based on methods described by Filmer et al. ${ }^{30}$ Data analysis included the calculation of proportions for all categorical variables. For continuous variables, means or medians were calculated. Variables were calculated for the entire sample across all strata, for each stratum as well as for certain variables, including educational status (for women), wealth quintile (for households) and gender (for children). Results were also presented for specific age groups for pregnant women, nonpregnant women and children. Unfortunately, an analysis of urban versus rural residences could not be performed because this classification does not exist in Oman's census data. Prevalence maps for stunting, wasting and overweight and obesity among children and underweight, overweight and obesity among women were presented according to WHO classifications. ${ }^{31}$

The statistical precision of prevalence rates was assessed using 95\% confidence intervals, which were calculated accounting for the complex sampling methods used in the survey. The significance of differences between subgroups was calculated using a Chi-squared test with weighted analysis and adjusted for complex sampling. Notably, VDD and VDI were merged to test for statistical significance between subgroups. This was due to the fact that deficiency and insufficiency are ranges on the same spectrum and therefore were not analysed separately. The level of statistical significance utilised throughout the analysis was set at $P<0.05$.

\section{ETHICS AND CONSENT}

The protocol of this study was granted ethical approval by the Research and Ethical Review and Approval Committee of the Oman Ministry of Health (\#MH/ DGP/R\&S/PROPOSAL_APPROVED/45/2015). Either the head of the household or, in their absence, another knowledgeable adult household member provided written informed consent prior to participation in the survey. All participants provided written informed consent before undergoing blood specimen collection and anthropometry measurements. Women aged 18-45 years gave consent for themselves, while consent on behalf of preschool children and girls aged 
15-17 years was given by a parent or legal guardian. Any documents containing identifying data such as completed questionnaires and blood collection sheets were kept in a locked cabinet at the Ministry of Health to maintain confidentiality and privacy.

\section{Results}

\section{HOUSEHOLD DATA}

Of the 3,862 households selected, data were collected from a total of 3,304 households (response rate: 85.6\%). The average number of household members was 6.9 individuals. Only $28.3 \%$ of the households owned agricultural land, while $43.2 \%$ owned livestock, mainly chickens, goats and sheep.

Overall, $89.9 \%$ of households had a safe water source, although $94.4 \%$ had access to safe water for drinking. Adequate sanitation and handwashing facilities with both soap and water were present in $85.2 \%$ and $97.4 \%$ of households, respectively. The most common types of oil used for cooking were sunflower oil (49.2\%), ghee (40.3\%), corn oil (38.8\%) and olive oil (38.7\%). At the time of the survey, $95.4 \%$ of households had cooking oil at home that was labelled as fortified. Of the $81.9 \%$ of households which had wheat flour in the house at the time of data collection, $95.1 \%$ of the flour was marked as fortified. Cooking oil and wheat flour consumption was calculated as $1.3 \mathrm{~L}$ and $3.4 \mathrm{~kg}$ per AME per month, respectively.

Consumption of cooking oil and wheat flour differed according to wealth quintile. Average cooking oil consumption per AME per month was significantly higher in households in the poorest wealth quintile compared to those in other wealth quintiles $(1.7 \mathrm{~L}$ versus $1.2-1.3 \mathrm{~L} ; P<0.001)$. In addition, consumption of wheat flour was significantly higher among members of households in poor wealth quintiles compared to those in wealthier households $(P<0.001)$. From the lowest to highest wealth quintiles, wheat flour consumption per AME per month was 5.2, 3.6, $3.4,3.4$ and $2.5 \mathrm{~kg}$.

\section{OMANI CHILDREN}

\section{Anaemia and Micronutrient Deficiencies}

The national prevalence rates of anaemia and micronutrient deficiencies among Omani children are presented in Table 1, while subgroup analyses by age, gender, governorate and wealth quintile are shown in Table 2. Overall, 23.8\% of the children were anaemic, with anaemia prevalence rates progressively decreasing with age and substantially varying by governorate, with the highest governorate-specific prevalence being more than two-fold higher than that of the lowest $31.3 \%$ in
Ad Dhahirah versus $15.4 \%$ in Dhofar; $P<0.010)$. The data indicate that a lower proportion of children living in the wealthiest households suffered from anaemia compared to those living in poorer households (17.4\% versus 24.0-27.5\%); however, this difference was not statistically significant $(P=0.060)$. Gender was not found to affect the prevalence of anaemia among Omani children.

Only $10.2 \%$ of children had ID and $1.6 \%$ had IDanaemia (IDA). Age was significantly associated with both ID and IDA prevalence ( $P<0.010$ each), with the highest prevalence rates of both conditions occurring in children aged $12-23$ months (17.4\% and 6.2\%, respectively) and $24-35$ months (12.1\% and 3.6\%, respectively). The prevalence rates of ID and IDA were highest in Dhofar (41.8\%) and Ash-Sharqiyah South (9.9\%), respectively; however, neither governorate had the highest prevalence of anaemia. Male children were significantly more likely to develop ID than female children (11.7\% versus 7.8\%; $P<0.050)$. Although not statistically significant, children living in wealthier households seemed to be more susceptible to ID than those in poorer households (10.3-15.4\% versus 4.9$7.9 \% ; P=0.099)$. However, there was no such trend with IDA.

Overall, $9.5 \%$ of the children had VAD, with significant differences between age groups. The prevalence of VAD in children aged 6-11 months was more than double that of older children $(23.5 \%$ versus 3.0-12.9\%; $P<0.010$ ). Considerable differences were also found between governorates, with prevalence rates ranging from $1.0 \%$ in Ad Dhahirah to $31.9 \%$ in Al-Wusta $(P<0.001)$. However, VAD prevalence did not differ substantially by gender. Although not statistically significant, VAD was more common in children in poorer households compared to those in wealthier households $(11.6-16.1 \%$ versus $7.0-7.6 \%$; $P$ $=0.081$ ).

The prevalence rate of VDD was 10.6\%; however, $53.8 \%$ of the children were classified as vitamin D-insufficient. There was no apparent change in the prevalence of VDD or VDI with age or household wealth; however, a significantly larger proportion of female children had VDD or VDI compared to male children (68.7\% versus 60.1\%; $P<0.050)$. Moreover, VDD or VDI varied substantially by governorate, ranging from $28.2 \%$ in Ad Dhahirah to $78.8 \%$ in Dhofar $(P<0.001)$. However, there was no statistically significant difference in vitamin $\mathrm{D}$ status between children with different levels of sun exposure, with $8.4 \%$ of children with the highest levels of sun exposure found to be vitamin D-deficient compared to $13.2 \%$ of children with the lowest levels. 
Table 1: Anemia, micronutrient indicators (6-59 months) and anthropometric measures (0-59 months), among Omani children

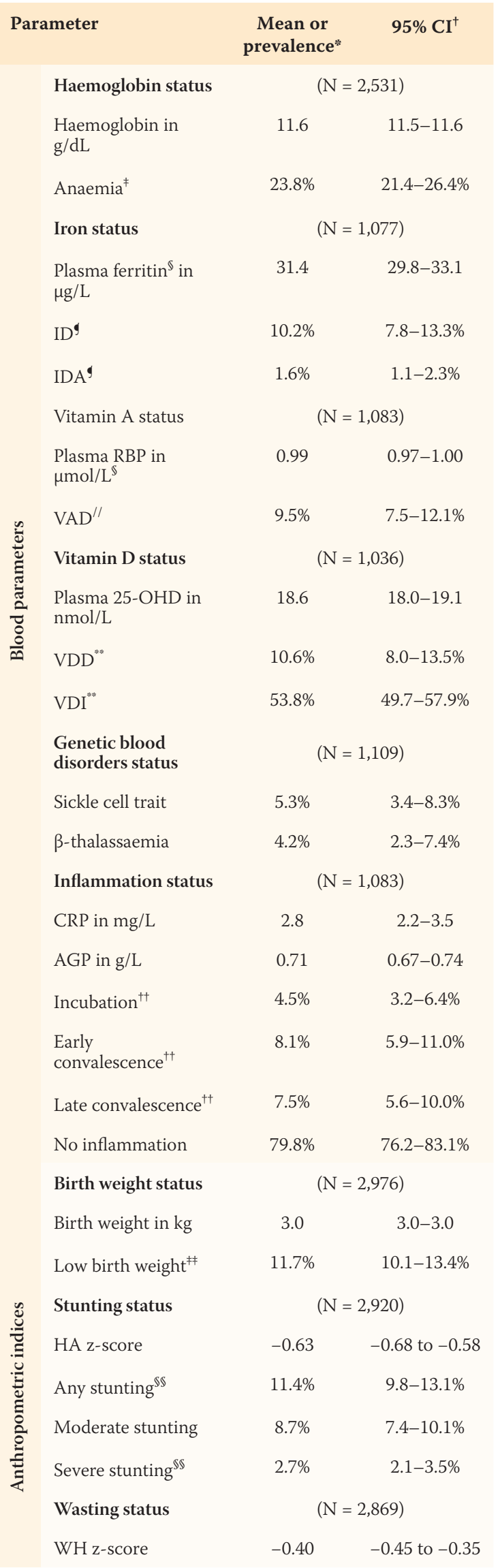

Table 1 (cont'd): Anemia, micronutrient indicators (6-59 months) and anthropometric measures (0-59 months), among Omani children

\begin{tabular}{|c|c|c|c|}
\hline \multicolumn{2}{|c|}{ Parameter } & \multirow{2}{*}{$\begin{array}{c}\begin{array}{c}\text { Mean or } \\
\text { prevalence }^{*}\end{array} \\
9.3 \%\end{array}$} & \multirow{2}{*}{$\begin{array}{c}\mathbf{9 5 \%} \mathbf{C I}^{\dagger} \\
7.9-11.0 \%\end{array}$} \\
\hline \multirow{14}{*}{ 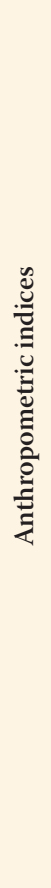 } & Any wasting & & \\
\hline & Moderate wasting & $6 ? \%$ & \\
\hline & & & \\
\hline & & $3.1 \%$ & \\
\hline & $\begin{array}{l}\text { Overweight and } \\
\text { obesity status }\end{array}$ & \multicolumn{2}{|c|}{$(\mathrm{N}=2,869)$} \\
\hline & Normal's & $86.5 \%$ & $84.7-88.1 \%$ \\
\hline & Overweight or & $4.2 \%$ & $3.4-5.1 \%$ \\
\hline & Overweight ${ }^{\text {gs }}$ & $3.1 \%$ & $2.4-4.0 \%$ \\
\hline & Obesity & $1.1 \%$ & $0.7-1.7 \%$ \\
\hline & Underweight status & \multicolumn{2}{|c|}{$(\mathrm{N}=2945)$} \\
\hline & Mean WA z-score & -0.64 & -0.71 to -0.57 \\
\hline & Any underweight ${ }^{\prime \prime \prime \prime}$ & $11.2 \%$ & $9.6-13.1 \%$ \\
\hline & $\begin{array}{l}\text { Moderate } \\
\text { underweight }\end{array}$ & $8.9 \%$ & $7.5-10.5 \%$ \\
\hline & $\begin{array}{l}\text { Severe } \\
\text { underweight }{ }^{\prime \prime \prime \prime}\end{array}$ & $2.4 \%$ & $1.7-3.3 \%$ \\
\hline
\end{tabular}

$C I=$ confidence interval; $I D=$ iron deficiency; IDA =ID-anaemia; $R B P=$ retinol-binding protein; $V A D=$ vitamin $A$ deficiency; $O H D=$ hydroxycholecalciferol; $V D D=$ vitamin $D$ deficiency; $V D I=$ vitamin $D$ insufficiency; $C R P=C$-reactive protein; $A G P=\alpha 1$-acid glycoprotein; $H A=$ heightfor-age; $W H=$ weight-for-height; $W A=$ weight-for-age.

*Means indicate unweighted counts while percentages were weighted for unequal probability of selection. ${ }^{\dagger}$ Considering the complex sampling design. ${ }^{\ddagger}$ Defined as altitude-adjusted haemoglobin levels of $<110 \mathrm{~g} / \mathrm{L}$. ${ }^{\circledR}$ Ferritin and RBP concentrations and associated deficiency prevalence rates were corrected for inflammation as per previously reported methods. ${ }^{18,19}$ - ID was defined as serum ferritin levels of $<12 \mu \mathrm{g} / \mathrm{L}$ and IDA as serum ferritin levels of $<12 \mu \mathrm{g} / \mathrm{L}$ and haemoglobin levels of $<110 \mathrm{~g} / \mathrm{L}$. "VAD was defined as RBP concentrations of $<0.73 \mu \mathrm{mol} / L$. VDD was defined as plasma 25-OHD levels of $<30 \mathrm{nmol} / \mathrm{L}$ and VDI as plasma 25-OHD levels of 30-49.9 nmol/L. ${ }^{+\dagger}$ Incubation was defined as CRP levels of $>5 \mathrm{mg} / \mathrm{L}$ and AGPlevels of $<1 \mathrm{~g} / \mathrm{L}$, early convalescence as CRPlevels of $>5 \mathrm{mg} / \mathrm{L}$ and AGP levels of $>1 \mathrm{~g} / \mathrm{L}$ and late convalescence as CRP levels of $\leq 5 \mathrm{mg} / \mathrm{L}$ and AGP levels of $>1 \mathrm{~g} / \mathrm{L}$. ${ }^{* \neq}$ Defined as $<2,500 \mathrm{~g}$. ${ }^{\mathbb{S}}$ Any stunting was defined as a HA z-score of less than-2 and severe stunting as a HA z-score of less than -3. "Any wasting was defined as a WHz-score of less than-2, severe wasting as a WH z-score of less than-3, normal as a WHz-score of -2 to 2, overweight as a WH z-score of 2-3 and obese as a WHz-score of $>3$. "II' Any underweight was defined as a WA $z$-score of $<2$ and severe underweight as a WA $z$-score of $<3$.

\section{Inflammation and Inherited Blood Disorders}

Inflammation was relatively rare, with $20.2 \%$ of children having one or more elevated inflammatory marker. However, $5.3 \%$ of children were affected by heterozygous or homozygous sickle cell disorders, while $4.2 \%$ were carriers of the $\beta$-thalassaemia trait.

\section{Anthropometric Indices}

The national prevalence rates of stunting, wasting and under- and overnutrition among Omani children are presented in Table 1. Approximately one-tenth of the children were stunted (11.4\%), wasted (9.3\%) or underweight (11.2\%). Although not statistically 
Table 2: Prevalence of anaemia and micronutrient deficiencies by demographic characteristics among Omani children aged 6-59 months

\begin{tabular}{|c|c|c|c|c|c|c|c|c|c|c|}
\hline \multirow[t]{2}{*}{ Characteristic } & \multicolumn{2}{|c|}{$\begin{array}{l}\text { Anaemia" } \\
(\mathrm{N}=2,523)\end{array}$} & \multicolumn{2}{|c|}{$\begin{array}{c}\mathrm{ID}^{\dagger} \\
(\mathrm{N}=1,074)\end{array}$} & \multicolumn{2}{|c|}{$\begin{array}{c}\mathrm{IDA}^{\dagger} \\
(\mathrm{N}=1,074)\end{array}$} & \multicolumn{2}{|c|}{$\begin{array}{l}\text { VDD or VDI }{ }^{\ddagger} \\
(\mathrm{N}=1,036)\end{array}$} & \multicolumn{2}{|c|}{$\begin{array}{c}\text { VAD }^{\S} \\
(\mathrm{N}=\mathbf{1 , 0 8 3})\end{array}$} \\
\hline & $\%$ & $95 \% \mathrm{CI}^{\prime \prime}$ & $\%$ & $95 \% \mathrm{CI}^{/ /}$ & $\%$ & $95 \% \mathrm{CI}^{/ /}$ & $\%$ & $95 \% \mathrm{CI}^{/ /}$ & $\%$ & $95 \% \mathrm{CI}^{/ /}$ \\
\hline Age in months & \multicolumn{2}{|c|}{$P<0.001^{* * *}$} & \multicolumn{2}{|c|}{$P<0.010^{\circ .3}$} & \multicolumn{2}{|c|}{$P<0.010^{m e n}$} & \multicolumn{2}{|c|}{$P=0.420^{\dagger \dagger}$} & \multicolumn{2}{|c|}{$P<0.010^{* n *}$} \\
\hline $6-11$ & 40.4 & $32.8-48.6$ & 5.3 & $2.1-12.5$ & 2.2 & $0.5-8.5$ & 62.6 & $47.5-75.6$ & 23.5 & $10.8-43.8$ \\
\hline $12-23$ & 33.4 & $27.8-39.5$ & 17.4 & $11.9-25.6$ & 6.2 & $3.6-10.6$ & 58.8 & $49.6-67.3$ & 3.0 & $1.6-5.6$ \\
\hline $24-35$ & 23.6 & $19.6-28.2$ & 12.1 & $7.9-17.9$ & 3.6 & $1.8-7.0$ & 64.1 & $55.6-71.7$ & 8.2 & $5.1-12.7$ \\
\hline $36-47$ & 15.0 & $11.4-19.5$ & 7.4 & $4.0-13.4$ & 1.1 & $0.4-3.0$ & 64.9 & $56.7-72.3$ & 10.0 & $6.7-14.8$ \\
\hline $48-59$ & 11.9 & $8.3-16.7$ & 4.9 & $2.6-9.0$ & 1.2 & $0.4-3.4$ & 70.3 & $62.5-77.0$ & 12.9 & $8.0-20.1$ \\
\hline Gender & \multicolumn{2}{|c|}{$P=0.881^{* * *}$} & \multicolumn{2}{|c|}{$P<0.050^{* * *}$} & \multicolumn{2}{|c|}{$P=0.173^{n * n}$} & \multicolumn{2}{|c|}{$P<0.050^{* * *}$} & \multicolumn{2}{|c|}{$P=0.802^{* * *}$} \\
\hline Male & 23.8 & $20.6-27.1$ & 11.7 & $8.6-15.7$ & 3.7 & $2.3-6.0$ & 60.1 & $54.7-65.2$ & 9.9 & $6.8-14.1$ \\
\hline Female & 24.0 & $20.8-27.5$ & 7.8 & $5.5-11.0$ & 2.2 & $1.2-4.1$ & 68.7 & $62.8-74.2$ & 9.2 & $6.4-13.1$ \\
\hline Governorate & \multicolumn{2}{|c|}{$P<0.010^{n+3}$} & \multicolumn{2}{|c|}{$P<0.001^{n s}$} & \multicolumn{2}{|c|}{$P<0.010^{n n}$} & \multicolumn{2}{|c|}{$P<0.001^{++}$} & \multicolumn{2}{|c|}{$P<0.001^{n *}$} \\
\hline Muscat & 18.1 & $9.9-30.7$ & 7.3 & $2.4-20.5$ & 0 & - & 65.9 & $53.1-76.7$ & 9.5 & $4.1-20.6$ \\
\hline Dhofar & 15.4 & $11.6-20.1$ & 41.8 & $29.8-54.8$ & 8.9 & $4.6-16.5$ & 78.8 & $68.1-86.6$ & 8.6 & $5.5-13.2$ \\
\hline Ad Dhakhiliyah & 29.5 & $25.6-33.6$ & 4.2 & $1.9-8.8$ & 1.7 & $0.4-6.4$ & 70.8 & $59.5-80.0$ & 10.0 & $6.1-16.0$ \\
\hline Ash Sharqiyah North & 25.4 & $18.9-33.1$ & 7.6 & $3.8-14.7$ & 2.9 & $1.0-8.1$ & 64.8 & $55.4-73.1$ & 7.6 & $3.6-15.4$ \\
\hline Ash Sharqiyah South & 23.5 & $17.6-30.7$ & 16.5 & $10.3-27.7$ & 9.9 & $5.0-18.8$ & 63.9 & $53.4-73.3$ & 18.9 & $12.9-26.7$ \\
\hline Al-Batinah North & 23.0 & $17.0-30.2$ & 6.1 & $2.6-13.4$ & 2.0 & $0.6-7.1$ & 66.7 & $56.4-75.5$ & 8.1 & $4.3-14.8$ \\
\hline Al-Batinah South & 25.7 & $20.3-32.0$ & 4.0 & $1.5-10.2$ & 1.0 & $0.1-6.9$ & 62.1 & $49.3-73.4$ & 10.0 & $3.9-23.2$ \\
\hline Ad Dhahirah & 31.3 & $24.6-38.9$ & 11.8 & $5.8-22.5$ & 2.9 & $0.7-11.3$ & 28.2 & $19.2-39.3$ & 1.0 & $0.2-5.1$ \\
\hline Al-Buraimi & 21.5 & $16.4-27.7$ & 3.4 & $1.5-7.4$ & 0.9 & $0.1-5.7$ & 63.8 & $53.1-73.3$ & 5.0 & $2.3-10.3$ \\
\hline Musandam & 22.3 & $17.1-28.5$ & 9.5 & $5.4-16.3$ & 2.4 & $0.7-8.3$ & 58.0 & $49.7-65.9$ & 11.9 & $7.1-19.3$ \\
\hline Al-Wusta & 23.3 & $19.2-27.9$ & 17.0 & $9.4-28.8$ & 8.5 & $3.5-19.0$ & 62.0 & $50.2-72.5$ & 31.9 & $22.2-43.5$ \\
\hline Wealth quintile & \multicolumn{2}{|c|}{$P=0.060^{* * *}$} & \multicolumn{2}{|c|}{$P=0.099^{* * *}$} & \multicolumn{2}{|c|}{$P=0.873^{n * n}$} & \multicolumn{2}{|c|}{$P=0.262^{\dagger+}$} & \multicolumn{2}{|c|}{$P=0.081^{* * *}$} \\
\hline Poorest & 27.5 & $21.1-34.8$ & 4.9 & $2.2-10.8$ & 3.3 & $1.1-9.3$ & 66.8 & $55.6-76.3$ & 11.6 & $6.0-21.2$ \\
\hline Poor & 25.6 & $21.1-30.6$ & 7.9 & $4.5-13.3$ & 2.3 & $1.2-4.7$ & 56.0 & $45.5-65.9$ & 16.1 & $11.0-22.9$ \\
\hline Middle & 24.0 & $19.6-28.9$ & 7.7 & $4.7-12.4$ & 3.8 & $1.7-8.4$ & 69.5 & $61.3-76.6$ & 8.3 & $4.4-15.1$ \\
\hline Wealthy & 26.6 & $21.0-33.1$ & 10.3 & $5.7-17.7$ & 3.3 & $1.6-6.7$ & 66.0 & $57.5-73.5$ & 7.6 & $4.3-13.3$ \\
\hline Wealthiest & 17.4 & $13.4-22.3$ & 15.4 & $9.5-23.9$ & 2.4 & $1.0-5.8$ & 66.5 & $57.2-74.6$ & 7.0 & $3.7-12.8$ \\
\hline
\end{tabular}

$I D=$ iron deficiency; IDA = ID-anaemia,$V D D=$ vitamin $D$ deficiency; VDI = vitamin $D$ insufficiency; $V A D=$ vitamin $A$ deficiency; $C I=$ confidence interval.

"Defined as altitude-adjusted haemoglobin levels of $<110 \mathrm{~g} / \mathrm{L}$. ${ }^{+} I D$ was defined as serum ferritin levels of $<12 \mu \mathrm{g} / \mathrm{L}$ and IDA as serum ferritin levels of $<12 \mu \mathrm{g} / \mathrm{L}$ and haemoglobin levels of $<110 \mathrm{~g} / \mathrm{L}$. Serum ferritin levels were corrected for inflammation as per previously reported methods. ${ }^{18}{ }^{7} V D D$ was defined as plasma 25-hydroxycholecalciferol levels of <30 nmol/L and VDI as plasma 25-hydroxycholecalciferol levels of 30-49.9 nmol/L. " Defined as retinol-binding protein concentrations of $<0.73 \mu \mathrm{mol} / \mathrm{L}$. Retinol-binding protein concentrations were corrected for inflammation as per previously reported methods. ${ }^{19}$ "Weighted for unequal probability of selection. "Considering the complex sampling design. "'P values of $<0.050$ indicate that at least one subgroup differs significantly from the others. ${ }^{\dagger}$ Overall P values for VDD and VDI by characteristic.

significant, stunting prevalence rates varied according to governorate. Furthermore, the children of short mothers $(<150 \mathrm{~cm})$ had a much higher prevalence of stunting compared to children of taller mothers (19.9\% versus 9.7\%; $P<0.001)$. Age, gender, household wealth and maternal education were not significantly associated with stunting.

The prevalence of wasting differed significantly by age group and was highest among children under 6 months and 6-11 months and lowest in children aged $12-23$ months ( $15.5 \%$ and $10.7 \%$ versus $6.2 \% ; P<0.050$ ). Although not statistically significant, the prevalence of wasting was highest in children living in the poorest households (14.7\%). Neither gender, governorate nor maternal education were determinants of wasting.

The prevalence of overweight or obesity was $4.2 \%$ and varied substantially by age. Children aged 6-11 and 12-23 months were significantly more likely to be overweight or obese compared to children aged 36-47 and $48-59$ months $(7.2 \%$ and $5.4 \%$ versus $1.8 \%$ and $2.1 \% ; P<0.010)$. Furthermore, differences were noted according to governorate. In addition, the prevalence of overweight or obesity progressively increased with household wealth from $1.6 \%$ in the poorest households 
Table 3: Micronutrient status indicators and prevalence of deficiencies among pregnant and non-pregnant Omani women aged $15-49$ years

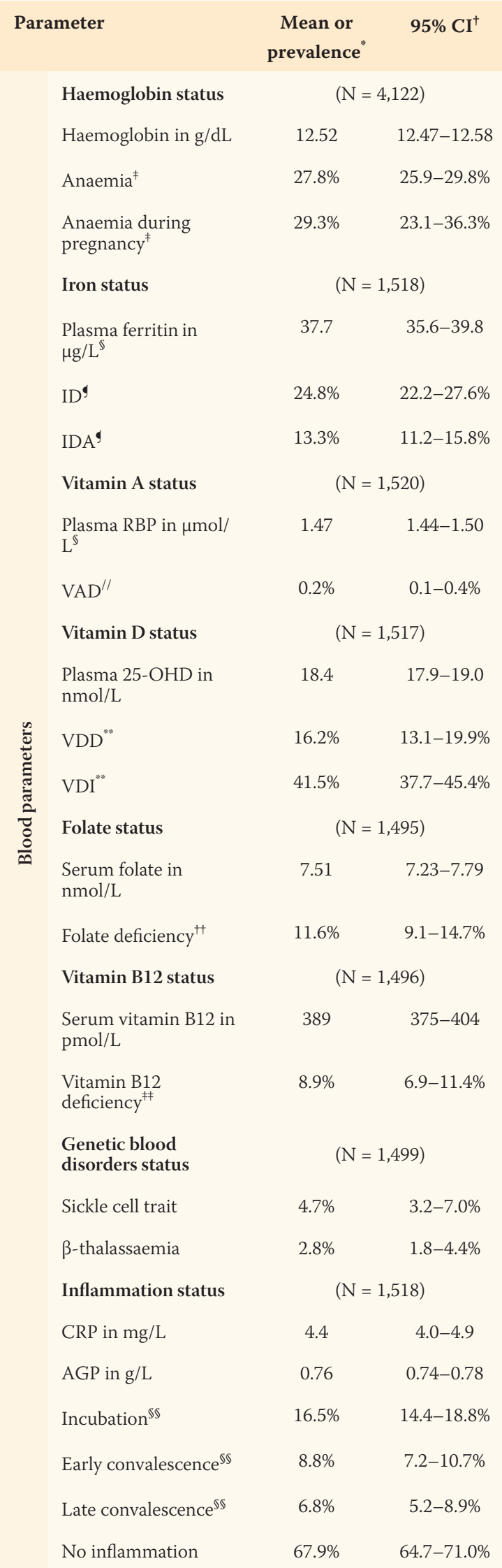

Table 3 (cont'd): Micronutrient status indicators and prevalence of deficiencies among pregnant and non-pregnant Omani women aged $15-49$ years

\begin{tabular}{|c|c|c|c|}
\hline \multicolumn{2}{|c|}{ Parameter } & Mean or & $95 \% \mathrm{CI}^{\dagger}$ \\
\hline \multirow{13}{*}{ 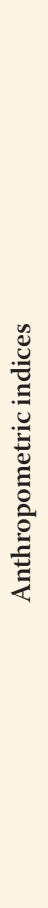 } & Undernutrition status & \multicolumn{2}{|c|}{$(\mathrm{N}=4,159)$} \\
\hline & Any undernutrition & $9.1 \%$ & $7.9-10.5 \%$ \\
\hline & $\begin{array}{l}\text { Severe } \\
\text { undernutrition } 9\end{array}$ & $1.6 \%$ & $1.1-2.2 \%$ \\
\hline & $\begin{array}{l}\text { Moderate } \\
\text { undernutrition } 9\end{array}$ & $2.3 \%$ & $1.8-3.0 \%$ \\
\hline & At risk ${ }^{99}$ & $5.2 \%$ & $4.3-6.2 \%$ \\
\hline & $\begin{array}{l}\text { Undernutrition } \\
\text { during pregnancy///I }\end{array}$ & $5.0 \%$ & $2.8-9.0 \%$ \\
\hline & $\begin{array}{l}\text { Overweight and } \\
\text { obesity status }\end{array}$ & \multicolumn{2}{|c|}{$(\mathrm{N}=4,159)$} \\
\hline & BMI in $\mathrm{kg} / \mathrm{m}^{2}$ & 27.5 & $27.1-27.8$ \\
\hline & Normal's & $31.7 \%$ & $29.9-33.5 \%$ \\
\hline & Overweight or obese & $59.2 \%$ & $57.1-61.4 \%$ \\
\hline & Overweight ${ }^{\text {s }}$ & $25.6 \%$ & $23.9-27.4 \%$ \\
\hline & Obese ${ }^{\boldsymbol{y}}$ & $33.6 \%$ & $31.7-35.6 \%$ \\
\hline & High WHR ${ }^{* * *}$ & $47.5 \%$ & $45.1-49.8 \%$ \\
\hline
\end{tabular}

$C I=$ confidence interval; $I D=$ iron deficiency; $I D A=I D$-anaemia $; R B P=$ retinol-binding protein; $V A D=$ vitamin $A$ deficiency; $O H D=$ hydroxycholecalciferol; $V D D=$ vitamin $D$ deficiency; $V D I=$ vitamin $D$ insufficiency; $C R P=C$-reactive protein; $A G P=\alpha 1$-acid glycoprotein; $B M I=$ body mass index; $W H R=$ waist-to-hip ratio.

*Means indicate unweighted counts while percentages were weighted for unequal probability of selection. ${ }^{\dagger}$ Considering the complex sampling design. ${ }^{7}$ Defined as altitude-adjusted haemoglobin levels of $<120 \mathrm{~g} / \mathrm{L}$ for nonpregnant women and $<110 \mathrm{~g} / \mathrm{L}$ for pregnant women. ${ }^{\mathbb{S}}$ Ferritin and RBP concentrations and associated deficiency prevalence rates were corrected for inflammation as per previously reported methods. 18,19 ID was defined as serum ferritin levels of $<12 \mu \mathrm{g} / L$ and IDA as serum ferritin levels of $<12 \mu \mathrm{g} / \mathrm{L}$ and haemoglobin levels of $<120 \mathrm{~g} / \mathrm{L}$. //Defined as RBP concentrations of $<0.73 \mu \mathrm{mol} / \mathrm{L}$. "VDD was defined as plasma 25-OHD levels of $<30 \mathrm{nmol} / \mathrm{L}$ and VDI as plasma 25-OHD levels of 30-49.9 $\mathrm{nmol} / \mathrm{L}$. ${ }^{+}$Defined as serum folate levels of $<10 \mathrm{nmol} / \mathrm{L}$. ${ }^{\neq \neq}$Defined as plasma $B 12$ levels of $<150 \mathrm{pmol} / \mathrm{L}$. "SI Incubation was defined as CRP levels of $>5 \mathrm{mg} / \mathrm{L}$ and AGP levels of $<1 \mathrm{~g} / \mathrm{L}$, early convalescence as CRP levels of $>5 \mathrm{mg} / \mathrm{L}$ and $A G P$ levels of $>1 \mathrm{~g} / \mathrm{L}$ and late convalescence as CRPlevels of $\leq 5 \mathrm{mg} / \mathrm{L}$ and AGP levels of $>1 \mathrm{~g} / \mathrm{L}$. "Severe undernutrition was defined as a BMI of $<16.0 \mathrm{~kg} / \mathrm{m}^{2}$, moderate undernutrition as a BMI of 16.0-16.9 $\mathrm{kg} / \mathrm{m}^{2}$, at risk of undernutrition as a BMI of $17.0-18.5 \mathrm{~kg} / \mathrm{m}^{2}$, normal as a BMI of $18.5-24.9 \mathrm{~kg} / \mathrm{m}^{2}$, overweight as a BMI of $25.0-29.9 \mathrm{~kg} / \mathrm{m}^{2}$ and obese as a BMI of $>30 \mathrm{~kg} / \mathrm{m}^{2}$. "II Defined as a mid-upper arm circumference of $<23.0 \mathrm{~cm}$. Defined as a WHR of $>0.85$.

to $5.5 \%$ in the wealthiest quintile $(P<0.050)$. Moreover, obesity or overweight was more common in children of mothers who had completed their secondary school education or higher (5.0\% versus $2.1-2.2 \%$; $P<0.050$ ). Figure 1 shows a prevalence map of stunting, wasting and overweight and obesity among Omani children by governorate. 
Table 4: Prevalence of anaemia and micronutrient deficiencies by demographic characteristics among non-pregnant Omani women aged $15-49$ years

\begin{tabular}{|c|c|c|c|c|c|c|c|c|c|c|c|c|}
\hline \multirow[t]{2}{*}{ Characteristic } & \multicolumn{2}{|c|}{$\begin{array}{l}\text { Anaemia" } \\
(\mathrm{N}=4,117)\end{array}$} & \multicolumn{2}{|c|}{$\begin{array}{c}\mathrm{ID}^{\dagger} \\
(\mathrm{N}=1,514)\end{array}$} & \multicolumn{2}{|c|}{$\begin{array}{c}\text { IDA }^{\dagger} \\
(\mathrm{N}=1,514)\end{array}$} & \multicolumn{2}{|c|}{$\begin{array}{l}\text { VDD or } \mathrm{VDI}^{\ddagger} \\
(\mathrm{N}=1,515)\end{array}$} & \multicolumn{2}{|c|}{$\begin{array}{c}\text { Folate } \\
\text { deficiency }^{\S} \\
(\mathrm{N}=1,493)\end{array}$} & \multicolumn{2}{|c|}{$\begin{array}{c}\text { VB12 } \\
\text { deficiency } \\
(\mathrm{N}=1,494)\end{array}$} \\
\hline & $\%^{\prime \prime}$ & $95 \% \mathrm{CI}^{*}$ & $\%^{\prime \prime}$ & $95 \% \mathrm{CI}^{* *}$ & $\% " 1$ & $95 \% \mathrm{CI}^{* *}$ & $\%^{\prime \prime}$ & $95 \% \mathrm{CI}^{* *}$ & $\%^{\prime \prime}$ & $95 \% \mathrm{CI}^{* * *}$ & $\%^{\prime \prime}$ & $95 \% \mathrm{CI}^{* *}$ \\
\hline Age in years & \multicolumn{2}{|c|}{$P<0.001^{\dagger+}$} & \multicolumn{2}{|c|}{$P<0.010^{\dagger+}$} & \multicolumn{2}{|c|}{$P<0.050^{\dagger \dagger}$} & \multicolumn{2}{|c|}{$P<0.001^{\text {抹 }}$} & \multicolumn{2}{|c|}{$P<0.050^{\dagger+}$} & \multicolumn{2}{|c|}{$P<0.050^{\dagger+}$} \\
\hline 15-19 & 28.8 & $24.1-34.0$ & 32.1 & $25.3-39.8$ & 14.3 & $9.7-20.7$ & 73.9 & $65.3-81.0$ & 13.7 & $9.0-20.3$ & 9.5 & $5.9-14.9$ \\
\hline $20-24$ & 20.5 & $16.8-24.8$ & 24.3 & $18.2-31.7$ & 12.8 & $8.1-19.6$ & 68.8 & $58.9-77.1$ & 18.8 & $\begin{array}{c}12.5- \\
27.3\end{array}$ & 12.4 & $8.0-18.7$ \\
\hline $25-29$ & 23.0 & $19.1-27.4$ & 13.7 & $9.5-19.4$ & 6.6 & $3.8-11.4$ & 54.1 & $45.2-62.7$ & 11.1 & $7.1-17.0$ & 10.5 & $6.4-17.0$ \\
\hline $30-34$ & 28.9 & $24.6-33.6$ & 22.9 & $16.8-30.4$ & 9.1 & $5.0-16.1$ & 54.1 & $44.3-63.6$ & 9.6 & $5.8-15.5$ & 11.1 & $7.5-16.1$ \\
\hline $35-39$ & 27.2 & $23.1-32.0$ & 25.4 & $19.2-32.8$ & 14.3 & $9.4-21.2$ & 52.1 & $41.9-62.1$ & 9.3 & $5.3-15.6$ & 8.1 & $4.3-14.7$ \\
\hline $40-44$ & 33.5 & $28.0-39.5$ & 32.1 & $23.8-41.8$ & 21.1 & $14.4-29.9$ & 46.7 & $38.0-55.6$ & 10.0 & $6.1-15.8$ & 5.7 & 3.0-10.6 \\
\hline $45-49$ & 38.6 & $31.7-46.0$ & 25.0 & $16.9-35.4$ & 18.6 & $11.4-28.9$ & 51.2 & $40.0-62.2$ & 6.1 & $3.1-11.7$ & 1.3 & $0.4-4.9$ \\
\hline Governorate & \multicolumn{2}{|c|}{$P<0.001^{\dagger \dagger}$} & \multicolumn{2}{|c|}{$P=0.193^{\dagger \dagger}$} & \multicolumn{2}{|c|}{$P<0.050^{\dagger \dagger}$} & \multicolumn{2}{|c|}{$P<0.001^{\text {㭋 }}$} & \multicolumn{2}{|c|}{$P<0.001^{+\dagger}$} & \multicolumn{2}{|c|}{$P<0.001^{\dagger \dagger}$} \\
\hline Muscat & 28.0 & $23.1-33.5$ & 27.2 & $21.1-34.2$ & 16.6 & $11.4-23.4$ & 44.1 & $35.4-53.1$ & 11.8 & $6.8-19.9$ & 2.0 & $0.7-5.5$ \\
\hline Dhofar & 28.0 & $23.1-33.5$ & 28.2 & $22.5-34.7$ & 9.0 & $6.2-12.9$ & 84.6 & $75.0-91.0$ & 47.7 & $\begin{array}{c}36.4- \\
59.3\end{array}$ & 20.0 & $10.2-35.5$ \\
\hline Ad Dhakhiliyah & 27.5 & $23.2-32.3$ & 16.1 & $9.4-26.3$ & 8.6 & $4.3-16.5$ & 49.5 & $38.6-60.3$ & 6.5 & $3.0-13.3$ & 3.2 & $0.8-12.8$ \\
\hline $\begin{array}{l}\text { Ash Sharqiyah } \\
\text { North }\end{array}$ & 24.6 & $9.5-30.5$ & 18.5 & $12.7-26.2$ & 9.6 & $5.8-15.5$ & 89.6 & $35.4-53.1$ & 2.9 & $0.9-9.2$ & 16.9 & $10.5-26.1$ \\
\hline $\begin{array}{l}\text { Ash Sharqiyah } \\
\text { South }\end{array}$ & 23.0 & $7.5-29.6$ & 25.5 & $19.6-32.5$ & 11.0 & $7.3-16.4$ & 84.8 & $75.0-91.0$ & 21.9 & $\begin{array}{c}15.0- \\
30.8\end{array}$ & 22.6 & $15.5-31.7$ \\
\hline $\begin{array}{l}\text { Al-Batinah } \\
\text { North }\end{array}$ & 32.6 & $27.6-38.1$ & 22.5 & $16.1-30.5$ & 14.7 & $9.1-23.0$ & 19.4 & $38.6-60.3$ & 7.3 & $3.7-14.1$ & 7.3 & $3.0-16.4$ \\
\hline $\begin{array}{l}\text { Al-Batinah } \\
\text { South }\end{array}$ & 29.5 & $24.5-35.0$ & 30.7 & $24.7-37.4$ & 15.7 & $10.3-23.2$ & 88.6 & $82.3-94.1$ & 1.6 & $0.4-6.3$ & 9.5 & $5.8-15.3$ \\
\hline Ad Dhahirah & 31.1 & $26.9-35.8$ & 33.1 & $24.2-43.4$ & 18.0 & $11.7-26.7$ & 81.2 & $75.5-91.0$ & 4.4 & $1.8-10.1$ & 4.4 & $1.1-15.7$ \\
\hline Al-Buraimi & 38.8 & $32.5-45.6$ & 28.3 & $19.0-40.0$ & 13.2 & $9.2-18.6$ & 70.7 & $13.7-26.6$ & 11.4 & $6.0-20.6$ & 21.5 & $14.6-30.6$ \\
\hline Musandam & 30.4 & $25.0-36.3$ & 31.5 & $20.9-44.4$ & 17.3 & $10.9-26.4$ & 80.9 & $81.3-93.3$ & 3.7 & $1.6-8.5$ & 10.6 & 7.9-13.9 \\
\hline Al-Wusta & 15.1 & $10.5-21.3$ & 27.8 & $20.2-36.9$ & 5.6 & $3.2-9.5$ & 37.0 & $72.7-87.5$ & 2.8 & $0.9-8.7$ & 13.0 & $6.1-25.3$ \\
\hline Wealth quintile & & $0.931^{+\dagger}$ & & $0.050^{\dagger+}$ & & $0.086^{\dagger+}$ & & $0.943^{\text {执 }}$ & & $0.781^{\dagger \dagger}$ & & $0.144^{\dagger \dagger}$ \\
\hline Poorest & 29.1 & $23.7-35.1$ & 28.8 & $19.5-40.3$ & 19.2 & $10.9-31.6$ & 52.9 & $39.3-66.1$ & 10.8 & $6.0-18.7$ & 9.3 & $5.2-16.1$ \\
\hline Poor & 27.3 & $23.0-32.1$ & 24.0 & $18.4-30.7$ & 14.6 & $10.2-20.5$ & 59.8 & $48.2-70.4$ & 9.0 & $5.0-15.6$ & 11.1 & $6.7-17.9$ \\
\hline Middle & 26.6 & $22.0-31.8$ & 15.3 & $10.0-22.7$ & 6.5 & $3.3-12.4$ & 57.0 & $46.6-66.9$ & 11.3 & $7.2-17.3$ & 12.8 & $8.2-19.4$ \\
\hline Wealthy & 27.5 & $23.8-31.6$ & 23.4 & $18.2-29.5$ & 13.2 & $9.1-19.0$ & 59.0 & $48.3-68.9$ & 11.5 & $7.5-17.2$ & 8.6 & $5.4-13.4$ \\
\hline Wealthiest & 28.9 & $25.6-32.5$ & 29.7 & $24.4-35.7$ & 15.1 & $11.1-20.3$ & 56.7 & $49.2-63.9$ & 13.0 & $8.8-18.8$ & 6.3 & $3.9-9.8$ \\
\hline
\end{tabular}

\section{OMANI WOMEN}

\section{Anaemia and Micronutrient Deficiencies}

The national prevalence rates of anaemia and micronutrient deficiencies among Omani women are presented in Table 3, while subgroup analyses by age, gender, governorate and wealth quintile among non-pregnant women are shown in Table 4 . Just under one-third of non-pregnant and pregnant women were anaemic (27.8\% and $29.3 \%$, respectively). Anaemia prevalence rates differed significantly by age 
A

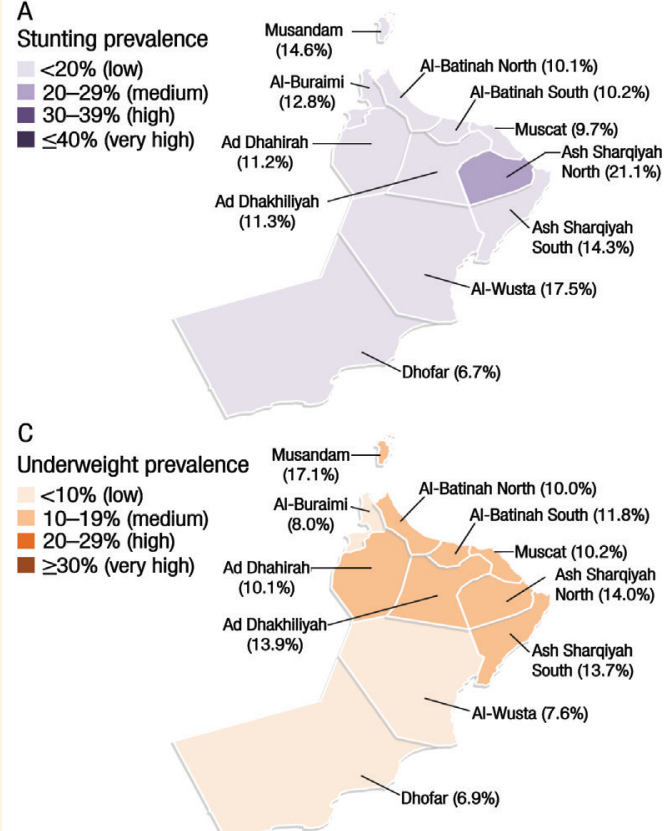

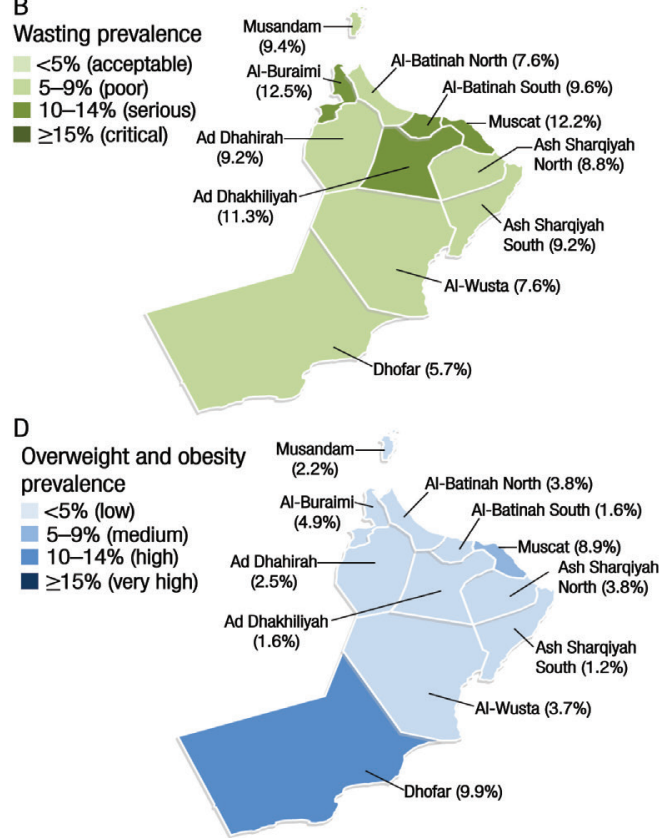

Figure 1: Prevalence maps of (A) stunting $(\mathrm{N}=2,920)$, (B) wasting $(\mathrm{N}=2,869),(\mathbf{C})$ underweight $(\mathrm{N}=2,945)$ and (D) overweight or obesity $(\mathrm{N}=2,869)$ among Omani children aged 0-59 months

Stunting, wasting and underweight categories were based on World Health Organization classifications. ${ }^{31}$

$(P<0.001)$ and were highest in non-pregnant women between $40-44$ and $45-49$ years old (33.5\% and 38.6\%, respectively). Furthermore, prevalence rates varied substantially among governorates, affecting only $15.1 \%$ of non-pregnant women living in Al-Wusta, but 38.8\% of those in Al-Buraimi $(P<0.001)$. Household wealth was not substantially associated with anaemia among non-pregnant women.

Overall, $24.8 \%$ of non-pregnant women were irondeficient, with 13.3\% suffering from IDA. Both ID and IDA were significantly associated with age $(P<0.010$ and $<0.050$, respectively); however, there was no clear trend in prevalence with increasing age. In addition, the prevalence of IDA differed significantly according to governorate, with prevalence rates ranging from 5.6\% in Al-Wusta to $18.0 \%$ in Ad Dhahirah $(P<0.050)$; however, the same did not hold true with regards to ID. Household wealth was significantly associated with ID $(P<0.050)$, although there was again no clear trend with regards to either increasing or decreasing wealth.

Among non-pregnant women, the prevalence rate of VDD was 16.2\%; however, $41.5 \%$ were vitamin D-insufficient. The prevalence of VDD or VDI varied substantially by age $(P<0.001)$, with the highest prevalence rates noted among women aged between $15-19$ and $20-24$ years ( $73.9 \%$ and $68.8 \%$, respectively). Furthermore, substantial differences were detected between governorates, with prevalence rates varying more than four-fold (19.4\% in Al-Batinah North versus $89.6 \%$ in Ash Sharqiyah North; $P<0.001)$. No significant association was observed between wealth quintile and vitamin D status.

Both folate and vitamin B12 deficiencies were present in approximately one-tenth of non-pregnant women (11.6\% and $8.9 \%$, respectively). There were significantly lower rates of both deficiencies in older women $(P<0.050$ each), with both folate and vitamin B12 deficiencies being lowest in women aged 4549 years $(6.1 \%$ and $1.3 \%$, respectively) and highest among those aged $20-24$ years (18.8\% and $12.4 \%$, respectively). In addition, significant differences were observed in folate deficiency prevalence rates between governorates $(P<0.001)$. In five governorates, including Ash Sharqiyah North, Al-Batinah South, Ad Dhahirah, Musandam and Al-Wusta, $<5 \%$ of women were folate-deficient; in contrast, the prevalence in Dhofar was $47.7 \%$. Similarly, there were significant differences between governorates in terms of vitamin B12 deficiency prevalence, with rates differing by more than 10-fold (2.0\% in Muscat versus 22.6\% in Ash Sharqiyah South).

\section{Inflammation and Inherited Blood Disorders}

Inflammation was more common among Omani women compared to Omani children, with $32.1 \%$ of women having at least one elevated inflammatory marker. In terms of haemoglobinopathies, $4.7 \%$ of women were affected by the sickle cell trait, while $2.8 \%$ were carriers of the $\beta$-thalassaemia trait. 


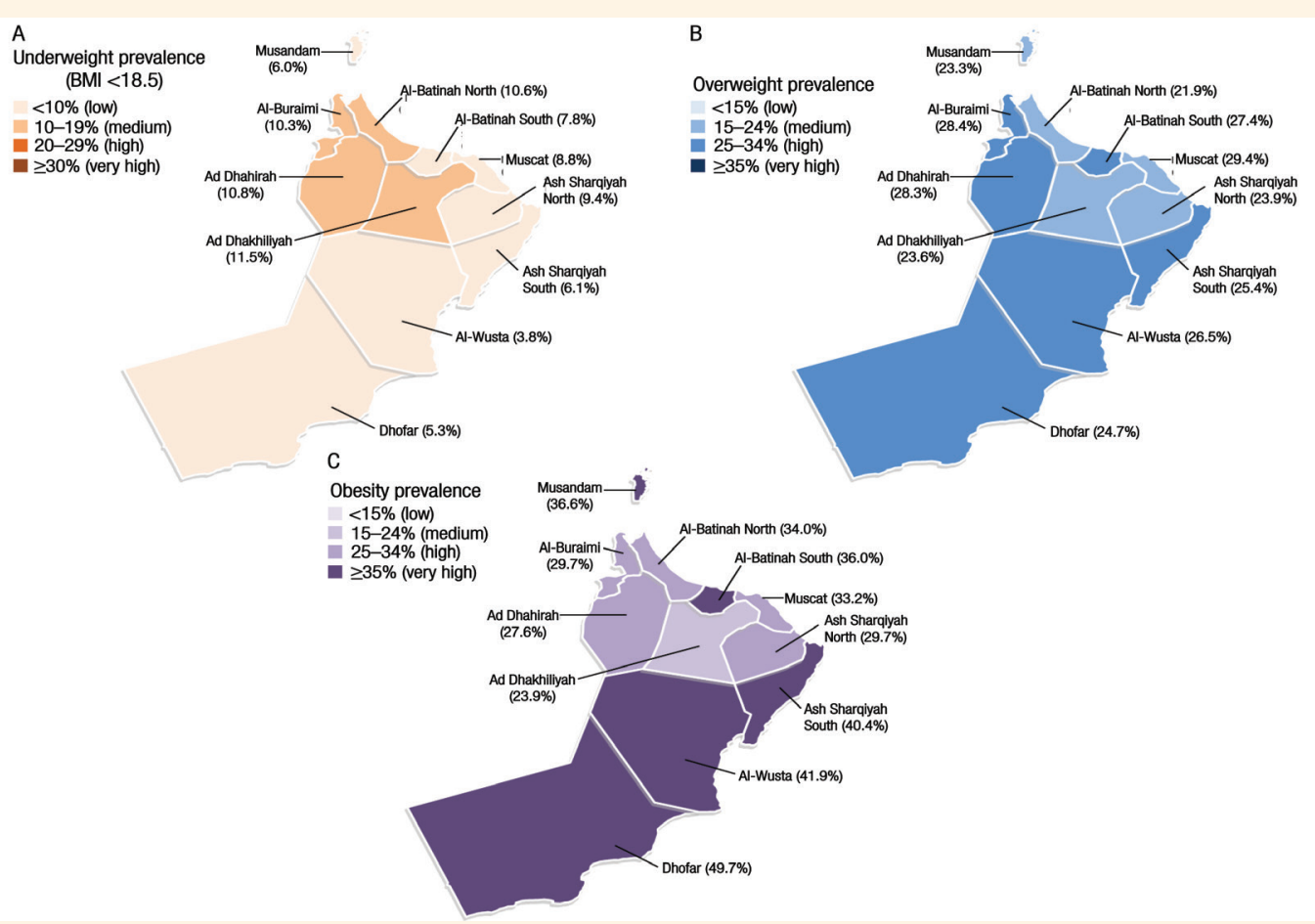

Figure 2: Prevalence maps of (A) underweight, (B) overweight and (C) obesity among non-pregnant Omani women aged $15-49$ years $(\mathrm{N}=4,159)$.

Underweight, overweight, and obesity categories were based on World Health Organization classifications. ${ }^{3 .}$

\section{Anthropometric Indices}

Prevalence rates of over- and undernutrition as well as mean BMI measurements for Omani women are presented in Table 3 . The prevalence of undernutrition in non-pregnant Omani women consistently decreased with age $(P<0.001)$, from $23.2 \%$ and $16.8 \%$ in women aged 15-19 and 20-24 years, respectively, to $1.1 \%$ and $0.4 \%$ in women aged $40-44$ and $45-49$ years, respectively. The prevalence of underweight differed significantly between governorates, with prevalence rates ranging from $3.8 \%$ in Al-Wusta to $11.5 \%$ in Ad Dhakhiliyah $(P<0.010)$. Overnutrition was very common in Omani women and its prevalence increased with age $(P<0.001)$. Only $25.7 \%$ of women aged 15-19 years were overweight or obese, compared to $40.1 \%$ and $54.0 \%$ of those aged $20-24$ and $25-29$ years, respectively, and $86.3 \%$ and $88.0 \%$ of those aged $40-44$ and $45-49$ years, respectively. Significant differences in overweight or obesity were also detected by governorate $(P<0.001)$. The waist-to-hip ratio was high in $47.5 \%$ of women, with similar patterns to rates of overweight or obesity. Figure 2 shows a prevalence map of underweight, overweight, and obesity among non-pregnant Omani women by governorate.

\section{Discussion}

According to the $\mathrm{WHO}$, the prevalence of anaemia in Omani children constitutes a moderate public health problem. ${ }^{7}$ In comparison to the results of the last national survey conducted in 2004, the prevalence of childhood anaemia was found to have halved in the ONNS, a finding which might be explained by the equally strong decline in ID prevalence over the same time period. ${ }^{12}$ Although not as pronounced as in children, the prevalence of anaemia among nonpregnant Omani women similarly dropped by almost $30 \%$. For both population groups, anaemia prevalence rates are in the same range as those reported by other countries in the Middle Eastern and North African region. ${ }^{32}$ In contrast, the rate of childhood ID_found to affect approximately one-tenth of children in the ONSS - can be classified as not prevalent in Oman. ${ }^{20}$ This could be due to the implementation of the national iron supplementation programme for children under two years of age.

The prevalence of concurrent anaemia and ID in Omani children was not higher than that expected from a random distribution of these two conditions. These results imply that iron deficiency does not have a contributory role in anaemia among Omani children. This finding contradicts the widely held assumption that $50 \%$ of anaemia cases arise due to ID, as well as the findings of a recent systematic analysis demonstrating that ID contributes to $25 \%$ of anaemia cases in many parts of the world. ${ }^{11}$ As such, the aetiology of anaemia in Omani children remains unclear. In contrast, ID contributed to $50 \%$ of the anaemia found in Omani 
women. Although the prevalence of ID in both children and women has decreased compared to findings from the 2004 national survey, this decrease was less apparent in women. ${ }^{12}$ The ONNS indicated that more than $80 \%$ of Omani women, but not children, consumed either tea or coffee or both daily. ${ }^{33}$ If these beverages are consumed before, during, or shortly after meals, they can inhibit non-haem-iron absorption, thereby contributing to ID. ${ }^{34}$

Nevertheless, the relatively high prevalence of ID noted in Omani women is somewhat surprising, considering that wheat flour fortification is mandatory in Oman. However, average wheat flour consumption was approximately $100 \mathrm{~g}$ per person per day, an amount which provides about $5 \mathrm{mg}$ of electrolytic iron per day. Using iron compounds with higher bioavailability, such as ferrous sulphate, sodium iron EDTA or ferrous fumarate, and/or increasing the concentration of the iron fortificant in wheat flour might have a positive effect on the iron status of Omani women. ${ }^{35}$ In fact, the WHO recommends that electrolytic iron not be used as a fortificant if average flour consumption is 75-149 g per person per day; instead, water-soluble forms or chelates of iron should be added to wheat flour at levels of 40-60 ppm. ${ }^{36}$

Nationally, VAD was almost non-existent among Omani women at a prevalence of $0.2 \%$, but could be considered a mild public health problem in children at 9.5\%. However, this does not apply to the governorates of Al-Wusta and Ash Sharqiyah South, where the public health significance of the rates of this childhood deficiency can be classified as severe and moderate, respectively. ${ }^{37}$ Since only a few women and children in Oman consume vitamin A or multivitamin supplements ${ }^{33}$, dietary vitamin A must come from vitamin A-rich foods and/or fortified vegetable oil. The food fortification programme in Oman mandates that all cooking oils and margarine be fortified. In the ONNS, women and children consumed an estimated $35 \mathrm{~mL}$ and $15 \mathrm{~mL}$, respectively, of vegetable oil daily. ${ }^{33}$ Such high levels of consumption of fortified oil likely contribute to the low prevalence of VAD. However, the high prevalence of VAD in children in Al-Wusta and Ash Sharqiyah South warrants further investigation, especially since Al-Wusta had the highest rate of oil consumption per capita. ${ }^{33}$ Accordingly, these governorates may need additional interventions targeted at children to increase consumption of vitamin A-rich and fortified foods.

Although approximately $60 \%$ of both children and women in Oman had VDD or VDI, most were cases of insufficiency rather than deficiency. The prevalence of VDD in Oman is low compared to other countries in the region. ${ }^{32}$ A national survey conducted in Jordan reported that $19.8 \%$ of children aged $12-59$ months and $60.3 \%$ of non-pregnant women of reproductive age were vitamin D-deficient. ${ }^{23,38}$ One of the reasons for the comparatively low prevalence of VDD in Oman might be the increased intake of vitamin D through the consumption of fortified vegetable oil. Both, the relatively high consumption of vegetable oil in Oman and the existing oil fortification policy enables access to enough vitamin $\mathrm{D}$ for most of the Omani population. Normally, vitamin D is primarily obtained via sun exposure, which may be limited among Omani women as most remain covered while outside of their homes. This may account for the lack of apparent association between sun exposure and vitamin D, ${ }^{33}$ unlike findings observed in Jordan. ${ }^{23,38}$ Further assessment of oil consumption practices and compliance with oil fortification policies in Oman could provide information as to whether the fortification levels should be adjusted or the quality control system strengthened to effectively improve the vitamin D status of Omani women and children. Moreover, adding vitamin $\mathrm{D}$ to wheat flour may be an effective strategy to complement vitamin D intake from fortified oil.

Both folate and vitamin B12 deficiencies were found to affect approximately one in 10 women in Oman. According to the current food fortification programme in Oman, $1.5 \mathrm{ppm}$ of folic acid is added to wheat flour; however, this level of fortification is below WHO guidelines which recommend a concentration of 2.6 ppm of folic acid if wheat flour consumption is between 75-149 g per person per day. ${ }^{36}$ Although rates of folate and vitamin B12 deficiencies among Omani women were relatively low, increasing the quantity of folic acid and including vitamin B12 fortificants to wheat flour could further reduce the rate of these deficiencies.

Prevalence rates of childhood stunting, wasting and underweight in the ONNS do not denote a severe public health problem in Oman; nevertheless, the rates of these nutritional issues have increased slightly since $2008 .^{3}$ In addition, rates of such problems in Oman are alarmingly high compared to recent data from other countries in the Middle East. ${ }^{39}$ The high incidence of low birth weight in Oman was, according to the WHO, within the range reported by the least economically developed countries in the world. ${ }^{40}$ In contrast to stunting, wasting in Omani children was highest in the first year of life, decreasing by about half by the second year of life. This is different from other countries where the average weight-for-height z-score begins to fall towards the end of the first year of life and remains low throughout the second year, due in part to poor complementary feeding. ${ }^{41}$ The early decline in weight-for-height $\mathrm{z}$-score in Oman could be due to poor breastfeeding practices, particularly a lack of exclusive breastfeeding. ${ }^{33}$ 
The national prevalence of overweight and obesity in Omani children in the ONNS was found to have increased since $2008 .^{3}$ Although childhood overweight and obesity prevalence rates are still not high, efforts should nevertheless be made to prevent further increases in the future. Overweight and obesity have been associated with type 2 diabetes mellitus (T2DM) in children and adolescents in Kuwait and Saudi Arabia. ${ }^{42,43}$ This chronic disease could become a public health problem in Oman in the near future if such prevalence rates continue to rise.

In contrast to children, the prevalence of overweight and obesity among Omani women was high. More than half of non-pregnant women aged 15-49 years were overweight or obese, with prevalence rates clearly increasing with age. Over the past few decades, Oman has experienced one of the sharpest increases in obesity prevalence worldwide. ${ }^{5}$ As with children, overweight and obesity is a key risk factor for T2DM, which has risen dramatically among women in Middle Eastern countries in the past two decades. ${ }^{44} \mathrm{~A}$ recent study estimated that $10-20 \%$ of Omani adults have T2DM. ${ }^{45}$ As overweight and obesity are also risk factors for cardiovascular diseases and various cancers, Oman may soon face a substantial rise in the incidence of several diseases linked to overnutrition. ${ }^{46}$ According to the WHO, while various societal and environmental factors influence excessive weight gain, lifestyle modifications in both dietary habits and physical activity levels can play a major role in preventing obesity. ${ }^{47}$

\section{Conclusion}

Although the national food fortification programme in Oman may already have helped to decrease the prevalence of several micronutrient deficiencies in children and women, further modifications might be key to alleviate those which still remain prevalent. It is therefore recommended that governmental organisations ensure that food vehicles are fortified according to international recommendations. Moreover, the food fortification programme should be revised to focus on governorates with high micronutrient deficiencies, such as Al-Wusta and Ash Sharqiyah South. Finally, governmental policies should address the alarmingly high rate of overweight and obesity among Omani women so as to mitigate the risk of chronic diseases linked to overnutrition, such as T2DM, cardiovascular diseases and various cancers.

\section{CONFLICT OF INTEREST}

The authors declare no conflicts of interest.

\section{FUNDING}

This study was funded by the UNICEF Oman.

\section{References}

1. United Nations Development Programme. Human development report 2010: The real wealth of nations - Pathways to human development. From:http://hdr.undp.org/sites/default/files/repo rts/270/hdr_2010_en_complete_reprint.pdf Accessed: Nov 2019.

2. Alasfoor D, Elsayed MK, Al-Qasmi AM, Malankar P, Sheth M, Prakash N. Protein-energy malnutrition among preschool children in Oman: Results of a national survey. East Mediterr Health J 2007; 13:1022-30. https://doi.org/10.26719/2007.13.5.1022.

3. Elsayed M, Al-Shammkhi S. Second national health survey for protein energy malnutrition in children below five years of age in the Sultanate of Oman: 2008-2009 analysis report. Muscat, Oman. From: https://groundworkhealth.org/wp-content/uploa ds/2020/04/ElSayed-2009_Second-National-Health-Surveyfor-PEM-in-Oman.pdf Accessed: Apr 2020.

4. United Nations Children's Fund. Health and nutrition status of Omani families (un-published). Muscat, Oman: United Nations Children's Fund, 1992.

5. Ng $\mathrm{M}$, Fleming $\mathrm{T}$, Robinson $\mathrm{M}$, Thomson $\mathrm{B}$, Graetz $\mathrm{N}$, Margono C, et al. Global, regional, and national prevalence of overweight and obesity in children and adults during 19802013: A systematic analysis for the Global Burden of Disease Study 2013. Lancet 2014; 384:766-81. https://doi.org/10.1016/ S0140-6736(14)60460-8.

6. Al Riyami A, Elaty MA, Morsi M, Al Kharusi H, Al Shukaily W, Jaju S. Oman World Health Survey: Part 1 - Methodology, sociodemographic profile and epidemiology of non-communicable diseases in Oman. Oman Med J 2012; 27:425-43. https://doi.org/10.5001/omj.2012.43.

7. World Health Organization. Worldwide prevalence of anaemia 1993-2005: WHO global database on anaemia. From: https:// apps.who.int/iris/bitstream/handle/10665/43894/978924 1596657_eng.pdf;sequence=1 Accessed: Nov 2019.

8. World Health Organization. Global nutrition targets 2025: Anaemia policy brief. From: https://apps.who.int/iris/bitstrea $\mathrm{m} /$ handle/10665/148556/WHO NMH_NHD 14.4 eng. pdf?ua=1 Accessed: Nov 2019.

9. Kassebaum NJ, Jasrasaria R, Naghavi M, Wulf SK, Johns N, Lozano R, et al. A systematic analysis of global anemia burden from 1990 to 2010. Blood 2014; 123:615-24. https://doi.org/10.11 82/blood-2013-06-508325.

10. Wirth JP, Petry N, Tanumihardjo SA, Rogers LM, McLean E, Greig A, et al. Vitamin A supplementation programs and cou-ntry-level evidence of vitamin A deficiency. Nutrients 2017; 9. https://doi.org/10.3390/nu9030190.

11. Petry N, Olofin I, Hurrell RF, Boy E, Wirth JP, Moursi M, et al. The proportion of anemia associated with iron deficiency in low, medium, and high human development index countries: A systematic analysis of national surveys. Nutrients 2016; 8:E693. https://doi.org/10.3390/nu8110693.

12. Oman Ministry of Health. National micronutrient status and fortified food coverage survey report. Muscat, Oman: Oman Ministry of Health, 2009. From: http://groundworkhealth.org/ wp-content/uploads/2020/04/MOH-2009 National-Foodfortification-coverage-survey.pdf Accessed: Apr 2020.

13. World Health Organization. Noncommunicable diseases and their risk factors: STEPwise approach to chronic disease risk factor surveillance (STEPS). From www.who.int/ncds/ surveillance/steps/en/ Accessed: Nov 2019.

14. Weisell R, Dop MC. The adult male equivalent concept and its application to Household Consumption and Expenditures Surveys (HCES). Food Nutr Bull 2012; 33:S157-62. https://doi.org/10.11 77/15648265120333S203 
15. Erhardt JG, Estes JE, Pfeiffer CM, Biesalski HK, Craft NE. Combined measurement of ferritin, soluble transferrin receptor, retinol binding protein, and C-reactive protein by an inexpensive, sensitive, and simple sandwich enzyme-linked immunosorbent assay technique. J Nutr 2004; 134:3127-32. https://doi.org/10.10 93/jn/134.11.3127.

16. Sullivan KM, Mei Z, Grummer-Strawn L, Parvanta I. Haemoglobin adjustments to define anaemia. Trop Med Int Health 2008; 13:1267-71. https://doi.org/10.1111/j.1365-3156.2008.02143.x.

17. World Health Organization. Haemoglobin concentrations for the diagnosis of anaemia and assessment of severity. From: www. who.int/vmnis/indicators/haemoglobin.pdf Accessed: Nov 2019.

18. Thurnham DI, McCabe LD, Haldar S, Wieringa FT, Northrop-Clewes CA, McCabe GP. Adjusting plasma ferritin concentrations to remove the effects of subclinical inflammation in the assessment of iron deficiency: A metaanalysis. Am J Clin Nutr 2010; 92:546-55. https://doi.org/10.39 45/ajcn.2010.29284.

19. Thurnham DI, McCabe GP, Northrop-Clewes CA, Nestel P. Effects of subclinical infection on plasma retinol concentrations and assessment of prevalence of vitamin A deficiency: Metaanalysis. Lancet 2003; 362:2052-8. https://doi.org/10.1016/S01 40-6736(03)15099-4.

20. World Health Organization. Serum ferritin concentrations for the assessment of iron status and iron deficiency in populations. From: www.who.int/vmnis/indicators/serum_ferritin.pdf Accessed: Nov 2019.

21. World Health Organization. Serum retinol concentrations for determining the prevalence of vitamin A deficiency in populations. From: www.who.int/vmnis/indicators/retinol.pdf Accessed: Nov 2019.

22. de Pee S, Dary O. Biochemical indicators of vitamin A deficiency: Serum retinol and serum retinol binding protein. J Nutr 2002; 132:2895S-901S. https://doi.org/10.1093/jn/132.9.2895S.

23. Nichols EK, Khatib IM, Aburto NJ, Serdula MK, Scanlon KS, Wirth JP, et al. Vitamin D status and associated factors of deficiency among Jordanian children of preschool age. Eur J Clin Nutr 2015; 69:90-5. https://doi.org/10.1038/ejcn.2014.142.

24. Gannagé-Yared MH, Maalouf G, Khalife S, Challita S, Yaghi Y, Ziade N, et al. Prevalence and predictors of vitamin D inadequacy amongst Lebanese osteoporotic women. Br J Nutr 2009; 101:487-91. https://doi.org/10.1017/S0007114508023404

25. de Benoist B. Conclusions of a WHO technical consultation on folate and vitamin B12 deficiencies. Food Nutr Bull 2008; 29:S238-44. https://doi.org/10.1177/15648265080292S129.

26. Cogill B. Anthropometric indicators measurement guide. From: www.fsnnetwork.org/anthropometric-indicators-measurementguide Accessed: Nov 2019

27. Shetty PS, James WPT. Body mass index: A measure of chronic energy deficiency in adults - FAO food and nutrition paper. From: www.fao.org/3/t1970e/t1970e00.htm Accessed: Nov 2019

28. Food and Nutrition Technical Assistance. Use of cutoffs for midupper arm circumference (MUAC) as an indicator or predictor of nutritional and health-related outcomes in adolescents and adults: A systematic review. From: www.fantaproject.org/sites/ default/files/resources/MUAC\%20Systematic\%20Review\%20 Nov\%2019.pdf Accessed: Nov 2019.

29. Addo OY, Stein AD, Fall CH, Gigante DP, Guntupalli AM, Horta BL, et al. Maternal height and child growth patterns. J Pediatr 2013; 163:549-54. https://doi.org/10.1016/j.jpeds.2013.02.002.

30. Filmer D, Pritchett LH. Estimating wealth effects without expenditure data--Or tears: An application to educational enrollments in states of India. Demography 2001; 38:115-32. https://doi.org/10.1353/dem.2001.0003.

31. World Health Organization. Nutrition landscape information system (NLIS): Country profile indicators - Interpretation guide. From: https://apps.who.int/iris/handle/10665/44397 Accessed: Nov 2019.
32. Hwalla N, Al Dhaheri AS, Radwan H, Alfawaz HA, Fouda MA, Al-Daghri NM, et al. The prevalence of micronutrient deficiencies and inadequacies in the Middle East and approaches to interventions. Nutrients 2017; 9:E229. https://doi.org/10.3390/ nu9030229.

33. Ministry of Health Oman, GroundWork \& UNICEF. Oman National Nutrition Survey 2017. (2018). From: http:// groundworkhealth.org/wp-content/uploads/2020/04/ONNS_ Report_2017.pdf Accessed: Apr 2020

34. Hurrell RF, Reddy M, Cook JD. Inhibition of non-haem iron absorption in man by polyphenolic-containing beverages. Br J Nutr 1999; 81:289-95. https://doi.org/10.1017/S0007114599000537.

35. World Health Organization. Guidelines on food fortification with micronutrients. From: www.who.int/nutrition/publications/g uide_food_fortification_micronutrients.pdf Accessed: Nov 2019.

36. World Health Organization. Recommendations on wheat and maize flour fortification: Meeting report - Interim consensus statement. From:www.who.int/nutrition/publications/micronu trients/wheat_maize_fort.pdf Accessed: Oct 2019.

37. World Health Organization. Global prevalence of vitamin A deficiency in populations at risk 1995-2005: WHO global database on vitamin A deficiency. From: https://apps.who. int/iris/bitstream/handle/10665/44110/9789241598019_eng. pdf?sequence=1 Accessed: Nov 2019.

38. Nichols EK, Khatib IM, Aburto NJ, Sullivan KM, Scanlon KS, Wirth JP, et al. Vitamin D status and determinants of deficiency among non-pregnant Jordanian women of reproductive age. Eur J Clin Nutr 2012; 66:751-6. https://doi.org/10.1038/ejcn.20 12.25 .

39. Nasreddine LM, Kassis AN, Ayoub JJ, Naja FA, Hwalla NC. Nutritional status and dietary intakes of children amid the nutrition transition: The case of the Eastern Mediterranean region. Nutr Res 2018; 57:12-27. https://doi.org/10.1016/j. nutres.2018.04.016.

40. World Health Organization. Global nutrition targets 2025: Low birth weight policy brief. From: https://apps.who.int/iris/ bitstream/handle/10665/149020/WHO_NMH_NHD_14.5 eng.pdf?ua=1 Accessed: Nov 2019.

41. Victora CG, de Onis M, Hallal PC, Blössner M, Shrimpton R. Worldwide timing of growth faltering: Revisiting implications for interventions. Pediatrics 2010; 125:473-80. https://doi.org/ 10.1542/peds.2009-1519.

42. Moussa MA, Alsaeid M, Abdella N, Refai TM, Al-Sheikh N, Gomez JE. Prevalence of type 2 diabetes mellitus among Kuwaiti children and adolescents. Med Princ Pract 2008; 17:270-5. https://doi.org/10.1159/000129604.

43. Al-Rubeaan K. National surveillance for type 1, type 2 diabetes and prediabetes among children and adolescents: A populationbased study (SAUDI-DM). J Epidemiol Community Health 2015; 69:1045-51. https://doi.org/10.1136/jech-2015-205710.

44. Abuyassin B, Laher I. Diabetes epidemic sweeping the Arab world. World J Diabetes 2016; 7:165-74. https://doi.org/10.4239/wjd. v7.i8.165.

45. Al-Lawati JA, Panduranga P, Al-Shaikh HA, Morsi M, Mohsin N, Khandekar RB, et al. Epidemiology of diabetes mellitus in Oman: Results from two decades of research. Sultan Qaboos Univ Med J 2015; 15:e226-33

46. Swinburn BA, Sacks G, Hall KD, McPherson K, Finegood DT, Moodie ML, et al. The global obesity pandemic: Shaped by global drivers and local environments. Lancet 2011; 378:804-14. https://doi.org/10.1016/S0140-6736(11)60813-1.

47. World Health Organization. Obesity: Preventing and managing the global epidemic - Report of a WHO consultation. From: www. who.int/nutrition/publications/obesity/WHO_TRS_894/en/ Accessed: Nov 2019. 